\title{
Mori Cortex Radicis extract inhibits human norovirus surrogate in simulated digestive conditions
}

\author{
Chae Yeon $\operatorname{Lim}^{1} \cdot$ Hyojin Kim ${ }^{1} \cdot$ Mi Sook Chung ${ }^{1}$
}

Received: 4 March 2021 / Revised: 13 July 2021 / Accepted: 27 July 2021/Published online: 29 August 2021

(C) The Korean Society of Food Science and Technology 2021

\begin{abstract}
Norovirus is a major cause of acute gastroenteritis globally, resulting in enormous health and societal costs. In this study, the antiviral activities of Mori Cortex Radicis (MCR) extract and its bioactive flavonoids, morusin and kuwanon $\mathrm{G}$, were tested against murine norovirus (MNV), a human norovirus surrogate, using plaque assay. The antiviral activity was confirmed in simulated digestive conditions, including simulated saliva fluid (SSF), simulated gastric fluid (SGF), and simulated intestinal fluid (SIF). Pre-treatment of MNV with MCR extract at $1000 \mu \mathrm{g} / \mathrm{mL}$ showed antiviral activity with a 1.1-log reduction. Morusin and kuwanon $\mathrm{G}$ also demonstrated a 1.0- $\log$ and 0.6-log reductions of MNV titers, respectively, at $100 \mu \mathrm{M}$. MCR extract at a concentration of $2 \mathrm{mg} / \mathrm{mL}$ in SSF, SGF, and SIF markedly reduced MNV titers by 1.8 , 1.9 , and $1.5 \operatorname{logs}$, respectively. Therefore, these data suggest that MCR extract can be used to control norovirus infectivity.
\end{abstract}

Keywords Murine norovirus - Mori Cortex Radicis · Morusin $\cdot$ Kuwanon G - Simulated digestive conditions

Mi Sook Chung

mschung@duksung.ac.kr

Chae Yeon Lim

soang205@naver.com

Hyojin Kim

durulove7@naver.com

1 Department of Food and Nutrition, Duksung Women's University, Seoul 01369, Korea

\section{Introduction}

Morus alba (the mulberry tree) is widespread in Asia, America, and Europe. The root bark of M. alba, Mori Cortex Radicis (MCR) has been used to treat jaundice, hematemesis, edema, and pulmonary inflammatory diseases in Asia (Lee et al., 2014; Seo et al., 2013). MCR reduces lipid peroxidation, enhances tyrosinase inhibitory activity, regulates the secretion and production of airway mucin, and promotes antioxidant activity (Kim et al., 2012; Lee et al., 2014; Singab et al., 2005; Zhu et al., 2019).

MCR is rich in phytochemicals such as flavonoids, benzofuran, and alkaloids (Lee et al., 2012). Morusin and kuwanon $\mathrm{G}$ are the biological marker compounds in MCR (Eom et al., 2017; Kim et al., 2015). Morusin, an isoprenylated flavone, reportedly possesses multifunctional bioactivities, including anti-allergic, anti-cancer, and lipogenesis inhibitory activities (Choi et al., 2020; Jin et al., 2019; Lee et al., 2018). Morusin demonstrates antimicrobial activity on Staphylococcus aureus (Pang et al., 2019). Notably, morusin is a potential inhibitor of the main protease $6 \mathrm{M} 03$ of severe acute respiratory syndrome coronavirus 2, which causes Coronavirus disease 2019 pandemic (Singh and Florez, 2020). Kuwanon G, another isoprenylated flavone, has antimicrobial activities on Streptococcus mutans, S. sobrinus, and S. sanguis, and Porphyromonas gingivalis (Park et al., 2003) and antiviral effect against human coronavirus 229E (Thabti et al., 2020).

Noroviruses belong to the Caliciviridae family and are a non-enveloped round virus with a positive-stranded RNA. Human noroviruses are a major cause of acute gastroenteritis globally and are estimated to cost $\$ 4.2$ billion and $\$ 60.3$ billion per year for direct health system costs and societal costs, respectively (Bartsch et al., 2016; Lindesmith et al., 2003). Noroviruses are rapidly transmitted 
through consumption of norovirus-contaminated food or water, contact with contaminated environmental surfaces, and person-to-person contact (Lindesmith et al., 2003). Norovirus foodborne outbreaks frequently occur in longterm care facilities, schools, hospitals, cruise ships, and the military. The most common symptoms are vomiting, watery diarrhea, and nausea. Norovirus is a leading cause of severe and chronic gastroenteritis in children younger than 5 years of age and immunocompromised persons (Bok and Green, 2012). Currently, no drugs or vaccines can effectively control and prevent norovirus infection.

Although human norovirus can grow in B-lymphocyte and stem cell-derived human enteroid culture systems, murine norovirus (MNV) shares biochemical and genetic features with human norovirus and is robust and a costeffective means for in vitro replication. MNV's these advantages make it widely used as a model for human norovirus infection (Ettayebi et al., 2016; Jones et al., 2014; Wobus et al., 2006).

Many research papers have been published on plantderived natural antivirals against norovirus, including black raspberry seed extract, grape seed extract, blueberry, aged green tea, and Artemisia princeps var. orientalis essential oil (Bae et al., 2018; Chung 2017; Falcó et al., 2019; Joshi et al., 2015, 2017). However, the antiviral activity of MCR and its constituents against norovirus has not been reported. To use plant-derived natural antivirals in food, it is essential to evaluate their antiviral activity in saliva and gastrointestinal fluids in different digestive enzyme conditions, salt concentrations, $\mathrm{pH}$ levels, and digestion times (Falcó et al., 2019; Joshi et al., 2015). In this study, we evaluated antiviral activities of MCR extract and its bioactive flavonoids, morusin and kuwanon $G$, in RAW 264.7 cells against MNV and then confirmed the antiviral activity of MCR extract under simulated in vitro human digestive conditions.

\section{Materials and methods}

\section{Materials}

Dimethyl sulfoxide, 3-(4,5-dimethylthiazol-2-yl)-2,5diphenyltetrazolium bromide (MTT), and formaldehyde were purchased from Sigma-Aldrich (St. Louis, MO, USA). Fetal bovine serum (FBS) was obtained from American Type Culture Collection (ATCC, Manassas, VA, USA). Dulbecco's modified Eagle's medium (DMEM) and penicillin-streptomycin (PS) were purchased from Gibco BRL (Karlsruhe, Germany). Morusin and kuwanon $\mathrm{G}$ were obtained from Biosynth Carbosynth ${ }^{\circledR}$ (Compton, UK). Human saliva $\alpha$-amylase (Type IX-A), porcine pepsin, porcine pancreatin, and bovine/ovine bile acid mixture were purchased from Sigma-Aldrich.

\section{Preparation of virus and cell}

RAW 264.7 cells (mouse leukemic macrophage cell line; RAW) were purchased from ATCC and grown in DMEM supplemented with $10 \% \mathrm{FBS}$ and $1 \% \mathrm{PS}$ at $37{ }^{\circ} \mathrm{C}$ in a $5 \%$ $\mathrm{CO}_{2}$ incubator. Dr. Herbert Virgin (Washington University School of Medicine, St. Louis, Missouri, USA) kindly provided murine norovirus-1 (MNV). MNV was inoculated in RAW 264.7 cells at $37^{\circ} \mathrm{C}$ for $1 \mathrm{~h}$ in a $5 \% \mathrm{CO}_{2}$ incubator, and then the viral inocula were discarded. DMEM supplemented with $10 \%$ FBS and $1 \%$ PS was added to the cells, which were incubated at $37{ }^{\circ} \mathrm{C}$ for $72 \mathrm{~h}$ in a $5 \% \mathrm{CO}_{2}$ incubator until we observed $\mathrm{MNV}$-induced cytopathic effects. The MNV-infected cells were frozen at $-80^{\circ} \mathrm{C}$ and thawed on ice, and then the cell lysates were collected and centrifuged. The supernatant was filtered using a $0.22 \mu \mathrm{m}$ syringe filter. For MNV purification, the filtered supernatant was centrifuged at $96,589 \times g$ (Beckman OptimaTM LE-80 K Ultracentrifuge, Beckman Coulter Inc. Indianapolis, IN, USA) using a 30\% sucrose solution for $3 \mathrm{~h}$ at $4{ }^{\circ} \mathrm{C}$. After centrifugation, the pellets were collected and dissolved in $20 \%$ glycerol. The purified MNV suspension was aliquoted and kept at $-80{ }^{\circ} \mathrm{C}$ until its use.

\section{Preparation of the MCR extract}

The dried root barks of $M$. alba (MCR; voucher no. DSNPL0018) were purchased from Booguk Co. (Seoul, Korea). The MCR extract was prepared as previously reported with minor modification (Eom et al., 2017). The MCR was ground into powder $(<1-\mathrm{mm}$ in size). $10 \mathrm{~g}$ of the MCR powder was extracted with $100 \mathrm{~mL}$ of $70 \%$ ethanol in an ultrasonic bath (Powersonic 420, Hwashin Instrument Co., Ltd. Seoul, Korea) at $20^{\circ} \mathrm{C}$ for $1 \mathrm{~h}$. The extract was centrifuged for $30 \mathrm{~min}(1610 \times g)$ at $4{ }^{\circ} \mathrm{C}$ and the supernatant was freeze-dried (IlShin BIOBASE, Seoul, Korea). The MCR extract yield (\%) was calculated as follows: the dry mass weight obtained after drying was divided by the dried bark weight used in the extraction and multiplied by 100 .

\section{Cell viability}

RAW 264.7 cells were grown $>90 \%$ confluent in 96-well culture plates. MCR extract underwent a tenfold serial dilution using DMEM. $10 \mu \mathrm{L}$ of MCR extract and $90 \mu \mathrm{L}$ of DMEM supplemented with $10 \%$ FBS and $1 \%$ PS were added to the cells. The cell plate was incubated for $12 \mathrm{~h}$ at $37{ }^{\circ} \mathrm{C}$ and $5 \% \mathrm{CO}_{2}$. The MTT solution was added to each well in the plate. After each plate was incubated for $1 \mathrm{~h}$, 
dimethyl sulfoxide was added to dissolve the formazan crystals. The absorbance at $570 \mathrm{~nm}$ was analyzed using a microplate reader (SpectraMax M2, Molecular Devices, San Jose, CA, USA). Cell viability (\%) was calculated as follows: the absorbance obtained after sample treatment was divided by the absorbance of the untreated control and multiplied by 100 . The MTT cell viability test was performed in triplicate.

\section{Antiviral effects of MCR extract, morusin, and kuwanon $\mathbf{G}$}

The antiviral effects of MCR extract and its flavonoids, morusin and kuwanon $\mathrm{G}$, were determined by plaque assay. A plaque assay was conducted to determine the viral titers as previously described (Bae et al., 2018). Confluent RAW 264.7 cell monolayers grown in 24-well plates were used for MNV inoculation. The MNV suspension (7-8 log PFU/ $\mathrm{mL})$ was incubated with MCR extract $(10-1000 \mu \mathrm{g} / \mathrm{mL})$ or its bioactive compound (morusin and kuwanon $\mathrm{G}$, $1-100 \mu \mathrm{M})$ at a volume ratio of $1: 1$ for $3 \mathrm{~h}$ at room temperature. The incubated suspension was tenfold serially diluted in DMEM and then inoculated onto confluent RAW 264.7 cell monolayers for $1 \mathrm{~h}$ at $37{ }^{\circ} \mathrm{C}$ and $5 \% \mathrm{CO}_{2}$. The inoculum was removed after $\mathrm{MNV}$ absorption, and $1 \mathrm{~mL}$ of DMEM supplemented with 5\% FBS, $0.5 \%$ PS, and $1 \%$ agarose overlay was added to each well. The plate was incubated for $48 \mathrm{~h}$ at $37{ }^{\circ} \mathrm{C}$ and $5 \% \mathrm{CO}_{2}$, and the cells were fixed with $500 \mu \mathrm{L}$ of $4 \%$ formaldehyde in phosphate buffered saline (PBS) for $1 \mathrm{~h}$ at $4{ }^{\circ} \mathrm{C}$. Next, the agarose overlay was discarded, and the cells were stained with 250 $\mu \mathrm{L}$ of $0.5 \%$ crystal violet solution in $25 \%$ methanol for $20 \mathrm{~min}$ at room temperature. The number of plaques in each well was counted under a light microscope. DMEM and 2-thiouridine (2TU) were used as untreated and positive controls, respectively (Bae et al., 2018). The plaque assay was performed in triplicate.

\section{Antiviral effect of MCR extract under simulated digestive conditions}

Antiviral effects of MCR extract in simulated digestive conditions were examined. Simulated digestive juices were prepared for the oral phase (simulated saliva fluid, SSF), gastric phase (simulated gastric fluid, SGF), and small intestinal phase (simulated intestinal fluid, SIF). The electrolyte solutions and digestive enzymes were prepared as previously reported (Minekus et al., 2014). Since each simulated digestive fluid was mixed with MNV suspension at a ratio of $1: 1(\mathrm{v} / \mathrm{v}), \mathrm{SSF}, \mathrm{SGF}$, and SIF were prepared at a $2 \mathrm{X}$ concentration. Briefly, SSF contained salivary $\alpha$ amylase (150 unit/mL) and was adjusted to a $\mathrm{pH}$ of 7 . SGF contained porcine pepsin $(4,000 \mathrm{unit} / \mathrm{mL})$ and was adjusted to a $\mathrm{pH}$ of 3 . And SIF had pancreatin (200 unit/mL) from porcine pancreas and bile $(20 \mathrm{mM})$ from bovine and ovine and was adjusted to a $\mathrm{pH}$ of 7 . The digestion procedures were carried out in the absence of light, and all incubations were performed in a shaking water bath at $37^{\circ} \mathrm{C}$ and $200 \mathrm{rpm}$. For the oral phase, MCR extract was dissolved in $1 \mathrm{~mL}$ of $\mathrm{SSF}$ and then was mixed with $1 \mathrm{~mL}$ of $\mathrm{MNV}$ suspension. The mixture was incubated for $2 \mathrm{~min}$. For the gastric and small intestine phases, MCR extract at $2 \mathrm{mg}$ / $\mathrm{mL}$ was dissolved in $1 \mathrm{~mL}$ of SGF or SIF and then was mixed with $1 \mathrm{~mL}$ of $\mathrm{MNV}$ suspension ( $7 \log \mathrm{PFU} / \mathrm{mL}$ ). The mixture was incubated for $2 \mathrm{~h}$, tenfold serially diluted in DMEM, and inoculated onto confluent RAW 264.7 cell monolayers for $1 \mathrm{~h}$ at $37^{\circ} \mathrm{C}$ and $5 \% \mathrm{CO}_{2}$. The starting MCR extract concentration was $0.2 \mathrm{mg} / \mathrm{mL}$. The remaining procedure was as described for the plaque assay method. Controls for each digestive phase were performed as described above without the MCR extract. The analysis of digestive condition was performed in triplicate.

\section{Data analysis}

The data were expressed as means \pm SD and analyzed by ANOVA. The mean values at the 5\% significance level were compared with a Tukey's test for multi-group comparison using IBM SPSS Statistics (version 24, IBM Corp, New York, NY, USA).

\section{Results and discussion}

\section{The yield of MCR extract and effects of MCR extract, morusin, and kuwanon $G$ on cell viability}

The yield of the lyophilized MCR, which was extracted with $70 \%$ ethanol, was $5.6 \%$ (w/w). It is well-known that kuwanon $\mathrm{G}$ and morusin are two major marker compounds of MCR, when extracted with $70 \%$ ethanol by ultrasonication (Eom et al., 2017; Kim et al., 2015). Eom et al. (2017) showed that kuwanon $\mathrm{G}$ and morusin are contained at $0.33 \%(\mathrm{w} / \mathrm{w})$ and $0.18 \%(\mathrm{w} / \mathrm{w})$ in MCR, respectively. The cell viability was performed to investigate whether MCR extract, morusin, or kuwanon G exert potential cytotoxicity in RAW 264.7 cells. The viabilities of RAW 264.7 cells were $\geq 98 \%$ after incubation with the extract at $1,000 \mu \mathrm{g} / \mathrm{mL}$ for $12 \mathrm{~h}$ (Fig. 1). Morusin and kuwanon $\mathrm{G}$ at $100 \mu \mathrm{M}$ showed $97 \%$ and $92 \%$ cell viabilities, respectively. The antiviral activity test of the extract, morusin, and kuwanon $\mathrm{G}$ was conducted at a concentration of above $90 \%$ of cell viability. 


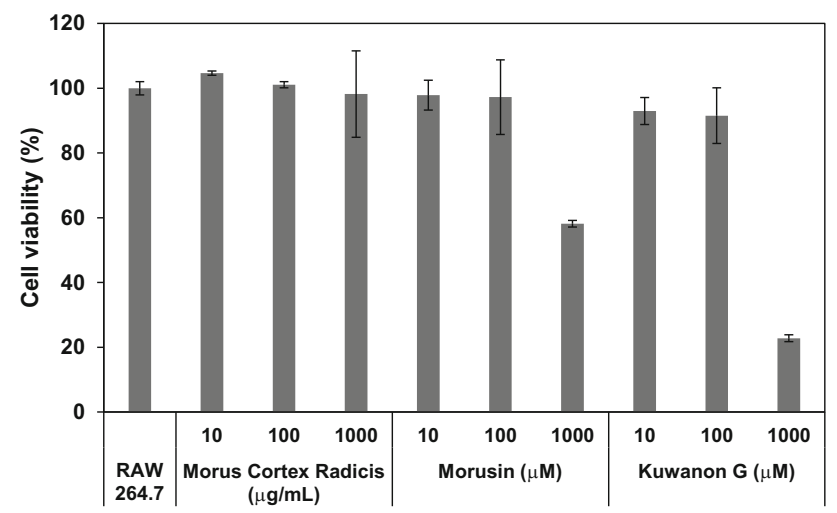

Fig. 1 The effects of Mori Cortex Radicis extract, morusin, and kuwanon $\mathrm{G}$ on cell viability. Cell viability was measured by MTT assay. RAW 264.7 cells were treated with MCR extract, morusin, and kuwanon $\mathrm{G}$ at different concentrations for $12 \mathrm{~h}$

\section{Antiviral effects of MCR extract, morusin, and kuwanon $\mathbf{G}$}

MCR extract showed dose-dependent inhibition at concentrations of $10-1,000 \mu \mathrm{g} / \mathrm{mL}$ and significant antiviral effect was achieved (a $1.1 \log$ reduction) at $1,000 \mu \mathrm{g} / \mathrm{mL}$ against MNV $(p<0.05)$ (Fig. 2A). A positive control, $2 \mathrm{TU}$ at $50 \mu \mathrm{M}$, revealed a $0.7 \log$ reduction of $\mathrm{MNV}$. Morusin showed 0.8, 0.9, and $1.0 \log$ reductions of MNV titers at 1, 10, and $100 \mu \mathrm{M}$, respectively (Fig. 2B). Kuwanon G showed 0.3 and $0.4 \log$ reductions of MNV titers at 1 and $10 \mu \mathrm{M}$, respectively, and a comparable strong antiviral effect was achieved (a $0.6 \log$ reduction) at $100 \mu \mathrm{M}(p<0.05)$ (Fig. 2C). These results demonstrate that the pre-treatment of MNV with MCR extract or its bioactive compounds, morusin and kuwanon G, significantly reduced MNV titers. These data suggest that the antiviral effect of MCR extract or its bioactive compounds on MNV can interfere with the attachment of MNV to the RAW cells or disrupt the virus particles.

\section{Antiviral activity of MCR extract in simulated digestive conditions}

Digestive conditions with low $\mathrm{pH}$, digestive enzymes, or bile reportedly cause chemical degradation or alteration of the antiviral compounds, leading to decreased antiviral activity (Falcó et al., 2019; Joshi et al., 2015, 2017). In this study, human digestive systems were simulated with a 3 -step in vitro process, including the oral, gastric, and small intestine systems. The antiviral test was performed in SSF, SGF, and SIF containing MNV in the presence or absence of MCR extract (Fig. 3). MCR extract at a concentration of $2 \mathrm{mg} / \mathrm{mL}$ in SSF, SGF, and SIF significantly reduced MNV titers by $1.8,1.9$, and 1.5 logs, respectively $(p<0.05)$, compared to no MCR extract. Interestingly,
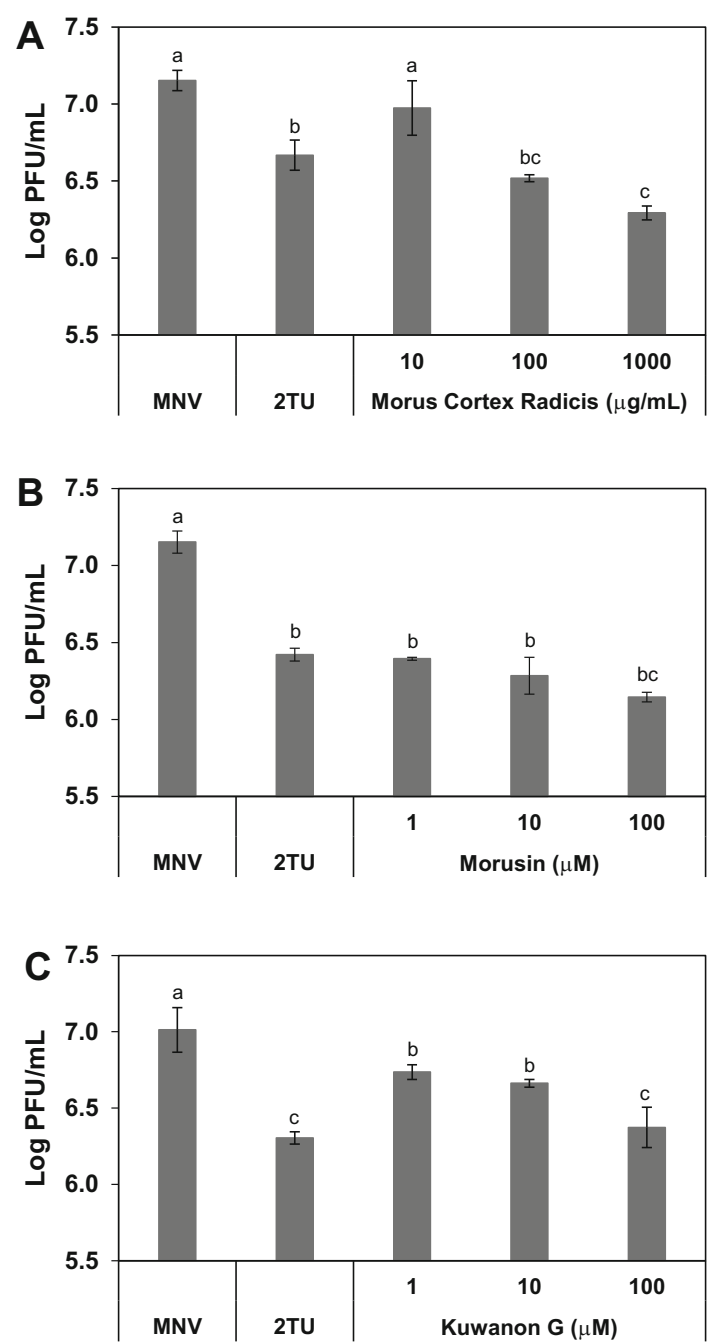

Fig. 2 Antiviral activities of Mori Cortex Radicis (MCR) extract, morusin, and kuwanon G against MNV. Different concentrations of (A) MCR extract, (B) morusin, and (C) kuwanon G were incubated with MNV for $3 \mathrm{~h}$ at room temperature prior to infection. Incubated the mixture was diluted with a tenfold dilution, and the diluted mixtures were infected onto monolayers of RAW 264.7 cells. DMEM and $2 \mathrm{TU}(50 \mu \mathrm{M})$ were used as untreated and positive controls, respectively. The different letters mean significant differences among the treatments $(p<0.05)$

there is no significant difference in MNV reduction titers between SSF and SGF $(p<0.05)$; while SSF contained salivary $\alpha$-amylase with only 2 min incubation at $\mathrm{pH} 7$, SGF contained porcine pepsin with $2 \mathrm{~h}$ incubation at $\mathrm{pH} 3$. It has been reported that $\mathrm{MNV}$ is relatively stable at acid $\mathrm{pH}$, reaching a $0.3-0.7 \mathrm{log}$ reduction of MNV for a $30 \mathrm{~min}$ incubation (Cannon et al., 2006; Hirneisen \& Kniel, 2013). Several research studies have also demonstrated that human norovirus is insusceptible to acid $\mathrm{pH}$ or pepsin. Dolin et al. (1972) reported that human norovirus incubated for $3 \mathrm{~h}$ at $\mathrm{pH} 2.7$ could infect human volunteers. When greenshell mussels were incubated with human noroviruses at $\mathrm{pH} 3.8$ for 4-weeks, the genome copies of human 


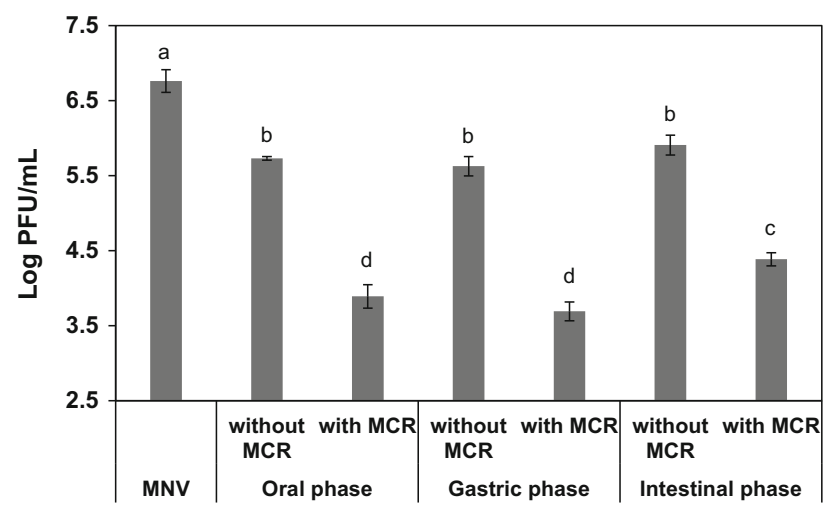

Fig. 3 Reduction of MNV titers after treatment with Mori Cortex Radicis (MCR) extract in simulated digestive conditions. After incubation of simulated salivary fluid (SSF), simulated gastric fluid (SGF), and simulated intestinal fluid (SIF) contained MNV in the presence or absence of MCR extract at $2 \mathrm{mg} / \mathrm{mL}$, respectively, MNV titers were evaluated using plaque assay. The different letters mean significant differences among the treatments $(p<0.05)$

norovirus did not decrease (Hewitt and Greening, 2004). It was recently found that the integrity of human norovirus GII.4 treated at $\mathrm{pH} 1.3$ alone and $\mathrm{pH} 1.3$ with pepsin did not change compared to the virus integrity after treatment at pH 8 (Chassaing et al., 2020). Therefore, MNV could mimic human norovirus' survival at low $\mathrm{pH}$ levels such as gastric conditions.

On the other hand, MCR extract showed antiviral activity, reaching a $1.5 \log$ reduction of $\mathrm{MNV}$ in the SIF containing pancreatin and bile at $\mathrm{pH}$ 7. Nelson et al. (2018) reported that bile acid facilitated MNV attachment and infection. In this study, MCR extract's antiviral activity in SIF containing bile was significantly lower than that of MCR extract in SSF or SGF $(p<0.05)$. Taken together, the results of the present study demonstrate that the antiviral activity of MCR extract could be maintained in the presence of digestive enzymes, a low $\mathrm{pH}$, and bile. Our results are consistent with previous findings that show antiviral effects of plant-derived extract or compounds in simulated digestive conditions. Aged-green tea extract at $5 \mathrm{mg} / \mathrm{mL}$ reduced $\mathrm{MNV}$ titer by $0.7,3.1$, and to an undetectable level in SSF (pH 7), SGF (pH 3), and SIF (pH 7), respectively (Falcó et al., 2019). Joshi et al. (2015) reported that $1 \mathrm{mg} / \mathrm{mL}$ grape seed extract reduced MNV titers to an undetectable level after $6 \mathrm{~h}$ incubation in SGF (pH 1.5) or SIF (pH 7). At $5 \mathrm{mg} / \mathrm{mL}$, blueberry proanthocyanidins reduced MNV titers to an undetectable level after $30 \mathrm{~min}$ incubation in SIF (pH 7) (Joshi et al., 2017).

The MCR is authorized for food supplement use in the European Union (European Commission 2021). The MCR extract can be added to sauces for ready-to-eat fresh salads or fresh oysters, which frequently cause norovirus outbreaks. In this context, further assessment of antiviral activities of the MCR extract in food matrices, when contaminated with human norovirus, as well as sensory evaluation of MCR extract-added foods is needed for future studies.

In conclusion, we identified the antiviral activities of MCR extract and its bioactive compounds, morusin and kuwanon G, against MNV in RAW 264.7 cells. The antiviral activity of MCR extract was also demonstrated in simulated digestive conditions, such as SSF, SGF, and SIF. Therefore, MCR extract can be used to reduce norovirus infectivity.

Acknowledgements This work was supported by the Duksung Women's University Research Grants in 2020.

\section{Declarations}

Conflict of interest None of the authors of this study has any financial interest or conflict with industries or parties.

\section{References}

Bae GR, Kim JW, Kim HJ, Seok JH, Lee DB, Kim KH, Chung MS. Inactivation of norovirus surrogates by kimchi fermentation in the presence of black raspberry. Food Control. 91:390-396 (2018)

Bartsch SM, Lopman BA, Ozawa S, Hall AJ, Lee BY. Global economic burden of norovirus gastroenteritis. PLoS One. 11: e0151219 (2016)

Bok K, Green KY. Norovirus gastroenteritis in immunocompromised patients. The New England Journal of Medicine. 367: 2126-2132 (2012)

Cannon JL, Papafragkou E, Park GW, Osborne J, Jaykus LA, Vinjé J. Surrogates for the study of norovirus stability and inactivation in the environment: a comparison of murine norovirus and feline calicivirus. Journal of Food Protection. 69: 2761-2765 (2006)

Chassaing M, Robin M, Loutreul J, Majou D, Belliot G, de Rougemont A, Boudaud N, Gantzer C. The effect of proteolytic enzymes and $\mathrm{pH}$ on GII.4 norovirus, during both interactions and non-interaction with histo-blood group antigens. Scientific Reports. 10: 17926 (2020)

Choi DW, Cho SW, Lee S-G, Choi CY. The beneficial effects of morusin, an isoprene flavonoid isolated from the root bark of Morus. International Journal of Molecular Sciences. 21: 6541 (2020)

Chung MS. Antiviral activities of Artemisia princeps var. orientalis essential oil and its $\alpha$-thujone against norovirus surrogates.Food Science and Biotechnology. 26: 1457-1461 (2017)

Dolin R, Blacklow NR, DuPont H, Buscho RF, Wyatt RG, Kasel JA, Hornick R, Chanock RM. Biological properties of Norwalk agent of acute infectious nonbacterial gastroenteritis. Proceedings of the Society for Experimental Biology and Medicine. 140: 578-583 (1972)

Ettayebi K, Crawford SE, Murakami K, Broughman JR, Karandikar U, Tenge VR, Neill FH, Blutt SE, Zeng XL, Qu L, Kou B, Opekun AR, Burrin D, Graham DY, Ramani S, Atmar RL, Estes MK. Replication of human noroviruses in stem cell-derived human enteroids. Science 353: 1387-1393 (2016)

Eom JH, Duyen Vu TP, Cai L, Zhao Y, Li HX, Yang SY, Kim YH, Kim SJ, Cho HS, Bao H, Chem J, Kim KT, Kang JS. Development of HPLC method for differentiation of three parts 
of mulberry tree. Analytical Science \& Technology. 30(3): 130-137 (2017)

European Commission. EU novel food catalogue. Available from: https://ec.europa.eu/food/safety/novel_food/catalogue/search/ public $/$ ?event $=$ home $\&$ seqfee $=184 \&$ ascii $=$ M. Accessed Jan. 02, 2021.

Falcó I, Randazzo W, Rodríguez-Díaz J, Gozalbo-Rovira R, Luque D, Aznar R, Sánchez G. Antiviral activity of aged green tea extract in model food systems and under gastric conditions. International Journal of Food Microbiology. 292: 101-106 (2019)

Hewitt $\mathbf{J}$ and Greening GE. Survival and persistence of norovirus, hepatitis A virus, and feline calicivirus in marinated mussels. Journal of Food Protection. 67: 1743-1750 (2004)

Hirneisen KA and Kniel KE. Comparing human norovirus surrogates: murine norovirus and tulane virus. Journal of Food Protection. 76: 139-143 (2013)

Jin SE, Ha H, Shin HK, Seo CS. Anti-allergic and anti-inflammatory effects of kuwanon $\mathrm{G}$ and morusin on MC/9 mast cells and HaCaT keratinocytes. Molecules 24: 265 (2019)

Jones MK, Watanabe M, Zhu S, Graves CL, Keyes LR, Grau KR, Gonzalez-Hernandez MB, Iovine NM, Wobus CE, Vinje J, Tibbetts SA, Wallet SM, Karst SM. Enteric bacteria promote human and mouse norovirus infection of B cells. Science 346: 755-759 (2014)

Joshi SS, Su X, D'Souza DH. Antiviral effects of grape seed extract against feline calicivirus, murine norovirus, and hepatitis A virus in model food systems and under gastric conditions. Food Microbiology. 52: 1-10 (2015)

Joshi SS, Howell AB, D'Souza DH. Blueberry proanthocyanidins against human norovirus surrogates in model foods and under simulated gastric conditions. Food Microbiology. 63: 263-267 (2017)

Kim JS, You HJ, Kang HY, Ji GE. Enhancement of the tyrosinase inhibitory activity of Mori Cortex Radicis extract by biotransformation using Leuconostoc paramesenteroides PR. Bioscience, Biotechnology, and Biochemistry. 76: 1425-1430 (2012)

Kim KT, Shin MC, Kim HH, Cho CW, Lee WJ, Woo ER, Kim KH, Kang JS. Specification and analysis of multiple marker compounds for quality control of Mori Cortex Radicis by HPLC. Bulletin of the Korean Chemical Society. 36: 117-122 (2015)

Lee HJ, Lyu DH, Koo U, Nam K-W, Hong SS, Kim KO, Kim $\mathrm{KH}$, Lee D, Mar W. Protection of prenylated flavonoids from Mori Cortex Radicis (Moraceae) against nitric oxide-induced cell death in neuroblastoma SH-SY5Y cells. Archives of Pharmacal Research. 35: 163-170 (2012)

Lee HJ, Ryu J, Park SH, Woo E-R, Kim AR, Lee SK, Kim YS, Kim J-O, Hong J-H, Lee CJ. Effects of Morus alba L. and natural products including morusin on in vivo secretion and in vitro production of airway MUC5AC mucin. Tuberculosis and Respiratory Diseases. 77: 65-72 (2014)

Lee MR, Kim JE, Choi JY, Park JJ, Kim HR, Song BR, Park JW, Kang MJ, Choi YW, Kim KM, Hwang DY. Morusin functions as a lipogenesis inhibitor as well as a lipolysis stimulator in differentiated 3T3-L1 and primary adipocytes. Molecules 23: $2004(2018)$
Lindesmith L, Moe C, Marionneau S, Ruvoen N, Jiang X, Lindblad L, Stewart P, LePendu J, Baric R. Human susceptibility and resistance to Norwalk virus infection. Nature Medicine. 9: 548-553 (2003)

Minekus M, Alminger M, Alvito P, Ballance S, Bohn T, Bourlieu C, Carrière F, Boutrou R, Corredig M, Dupont D, Dufour C, Egger L, Golding M, Karakaya S, Kirkhus B, Le Feunteun S, Lesmes U, Macierzanka A, Mackie A, Marze S, McClements DJ, Ménard O, Recio I, Santos CN, Singh RP, Vegarud GE, Wickham MS, Weitschies W, Brodkorb A. A standardised static in vitro digestion method suitable for food - an international consensus. Food \& Function. 5: 1113-1124 (2014)

Nelson CA, Wilen CB, Dai YN, Orchard RC, Kim AS, Stegeman RA, Hsieh LL, Smith TJ, Virgin HW, Fremont DH. Structural basis for murine norovirus engagement of bile acids and the CD300lf receptor. Proceedings of the National Academy of Sciences of the United States of America. 115: E9201-E9210 (2018)

Pang D, Liao S, Wang W, Mu L, Li E, Shen W, Liu F, Zou Y. Destruction of the cell membrane and inhibition of cell phosphatidic acid biosynthesis in Staphylococcus aureus: an explanation for the antibacterial mechanism of morusin. Food \& Function. 10: 6438-6446 (2019)

Park KM, You JS, Lee HY, Baek NI, Hwang JK. Kuwanon G: An antibacterial agent from the root bark of Morus alba against oral pathogens. Journal of Ethnopharmacology. 84: 181-185 (2003)

Seo C-S, Lim H-S, Jeong S-J, Ha H, Shin H-K. HPLC-PDA analysis and anti-inflammatory effects of Mori Cortex Radicis. Nature Product Communications. 8: 1443-1446 (2013)

Singab AN, El-Beshbishy HA, Yonekawa M, Nomura T, Fukai T. Hypoglycemic effect of Egyptian Morus alba root bark extract: effect on diabetes and lipid peroxidation of streptozotocininduced diabetic rats. Journal of Ethnopharmacology. 100: 333-338 (2005)

Singh S and Florez H. Coronavirus disease 2019 drug discovery through molecular docking. F1000Research. 9: 502 (2020)

Thabti I, Albert Q, Philippot S, Dupire F, Westerhuis B, Fontanay S, Risler A, Kassab T, Elfalleh W, Aferchichi A, Varbanov M. Advances on antiviral activity of Morus spp. plant extracts: human coronavirus and virus-related respiratory tract infections in the spotlight. Molecules. 25: 1876 (2020)

Wobus CE, Thackray LB, Virgin HW 4th. Murine norovirus: a model system to study norovirus biology and pathogenesis. Journal of Virology. 80: 5104-5112 (2006)

Zhu W, Zhong Z, Liu S, Yang B, Komatsu S, Ge Z, Tian J. Organspecific analysis of Morus alba using a gel-free/label-free proteomic technique. International Journal of Molecular Sciences. 20: 365 (2019)

Publisher's Note Springer Nature remains neutral with regard to jurisdictional claims in published maps and institutional affiliations. 